\title{
Effectiveness of Educational Module of Autism Spectrum Disorder (EMASD) in Identifying Children with ASD among preschool teachers: A Study Protocol for Parallel Cluster-Randomized Controlled Trial feasibility study
}

Sahar Mohammed Taresh ( $\nabla$ sahartaresh30@gmail.com )

Taiz University https://orcid.org/0000-0002-6541-0110

Nor Aniza Ahmad

UPM - Serdang: Universiti Putra Malaysia

Samsilah Roslan

UPM - Serdang: Universiti Putra Malaysia

Aini Marina Ma'rof

UPM - Serdang: Universiti Putra Malaysia

sumaia mohammed Zaid

Sana'a University

Study protocol

Keywords: Autism, preschool teachers, educational module, knowledge, belief, identification skills, selfefficacy, Yemen

Posted Date: September 29th, 2021

DOl: https://doi.org/10.21203/rs.3.rs-923156/v1

License: (c) (i) This work is licensed under a Creative Commons Attribution 4.0 International License. Read Full License 


\section{Abstract}

Background: Increasing efforts have been focused on providing a quality education for children with Autism Spectrum Disorder (ASD) after identifying them at an early stage. Preschool teachers play a major role in the main ASD identification system as they represent the gatekeepers to identify and refer any children suspected of ASD to specialists. However, there is little literature available on the ability of preschool teachers of their perception regarding this role.

Aim: The main objective of this study is to evaluate the feasibility and acceptability of an educational module to identify children with ASD (EMASD). The second objective is to assess the initial impact of the EMASD on improving preschool teacher's ability to identify children with ASD in a normal school.

Method: This pilot study will examine the feasibility of the randomised controlled trial (RCT) using EMASD as an intervention. The intervention will be ten weekly group-based sessions designed to improve the knowledge, belief, identification skills, and self-efficacy to identify children with ASD among Yemeni preschool teachers. The teachers will be randomly assigned to the intervention group that will receive the EMASD and the control group without any intervention. The feasibility will be determined based on the effectiveness as measured by questionnaires and open-ended questions. General linear measurement (GLM) will be used to compare the outcome scores in the questionnaire between the two groups and within the group whereas thematic analysis will be used to analyse the open-ended questions.

Expected outcomes: The findings from this study will give critical empirical data about the feasibility of EMASD.

Discussion: EMASD has the potential to increase the ability of preschool teachers to detect children with ASD. The findings from the feasibility study will be utilised to improve the research protocol of the randomised controlled trial and to ensure a better design of an intervention for a larger powered trial in the future.

\section{Contributions To The Literature}

- EMASD will enhance the early identification of children with ASD.

- Prepared preschool teachers through EMASD will enhance referral of a child to intervention service

- Using EMASD will reduce the preschool teachers' stress about ASD child's behavior.

- The current study will establish baseline information of preschool teachers for detecting ASD that will be benefited for other researchers who aim to investigate ASD diagnosis, screening, or inclusive system.

- EMASD would also increase the teachers' willingness towards the inclusive of children with ASD.

\section{Introduction}


Early identification of children with autism spectrum disorder (ASD) is a practical and important step to improve the wellbeing of children with autism and their family members (1). Evidence in the literature has largely been supportive of early detection efforts in view of the benefits of early access to evidence-based interventions for autism (2-4). Early detection of ASD can also potentially alleviate or even prevent the obstacles associated with ASD symptoms, thus minimising the cost besides enhancing the quality of life and productivity of children with $\operatorname{ASD}(5,6)$.

However, there are controversies and challenges surrounding this matter. Barriers and obstructions to the successful implementation of early detection programme of ASD children are present at both societal (level of awareness and acceptance among children and family members etc.) and individual (visibility of ASD symptoms, adaption and assimilation into society, etc.) levels. These factors can lead to late detection of ASD (1). In many ways, preschool teachers play an important role in the early identification of ASD children. Nevertheless, very little information is available about their perceptions and capabilities in performing this role $(7,8)$. In order to acquire a clear view on this matter and to understand the challenges faced by preschool teachers in identifying children with ASD, several vital questions need to be answered.

\section{Q1: How does early identification affect a child with ASD?}

In view of the positive effects of early ASD detection as mentioned above, an enhanced system of early ASD identification is pivotal to facilitate earlier intervention that has been shown to improve core behavioural and skill deficits related to ASD (9). To achieve early identification, there is an urgent need to address the long waiting list and the lack of ASD knowledge among child care providers in education agencies $(7,9)$. Many studies reported an average age of ASD diagnosis only at 52 and 55 months, i.e. the nursery stage $(10,11)$. Interestingly, the idea of ASD screening among children by educational agencies before referral to clinicians was well received by parents, caregivers, and stakeholders $(12,13)$. Thus, it may be feasible for teachers to assist in the early detection of children with ASD to reduce the long wait-time for diagnostic evaluation that prevents the children from receiving early ASD intervention. Consequently, early detection of children with ASD by preschool teachers can be introduced as an alternative to the "wait-to-fail" model $(7,14)$. This is also supported by recent research that emphasised the important roles of preschool teachers in the early detection of children with ASD $(1,7)$. Therefore, it is necessary to obtain a broad and clear understanding of the preschool teachers' role in early identification in ASD, leading to the second question.

\section{Q2: What is preschool teachers' role in identifying children with ASD?}

As mentioned above, there is a need to improve teachers' ability in the early detection and identification of children with ASD. Preschool teachers who work with children 2-7 years old are exceptionally wellpositioned to identify children with ASD before the formal diagnosis can be made (15-17). As preschool teachers, they play a central role in the early detection and referral of developmental, behavioural, and emotional issues in children $(18,19)$. As they are in close contact with the children, preschool teachers have a higher likelihood of recognising any childhood disorders and recommend the parents to bring the 
children for suitable assessment that will lead to early intervention services if necessary (20). To achieve that, preschool teachers must be able to assess a child's development and to compare the development with the child's peers (13). Very often, preschool teachers' observation is a reliable source of information about the ASD symptoms compared to the parents due to their ability to compare between the children in the class in terms of development, as proven in many studies $(21,22)$. However, some preschool teachers may incorrectly identify symptoms of ASD as symptoms of Attention Deficit and Hyperactivity Disorders (ADHD) (23). Although schools and preschools are ideal settings for screening and identification of childhood disability, only $4 \%$ of students in the education system had been formally diagnosed with a disability (24). The numerous obstacles faced by preschool teachers in identifying and referring these children for assessment might be the reason behind the low rate of diagnosis (25-27). To understand the challenges encountered by preschool teachers in identifying children with ASD, it is necessary to explore the relevant obstacles and challenges.

\section{Q3. What are the challenges that preschool teachers face in identifying children with ASD?}

While teachers may be well-positioned to identify early challenges faced by their students, multiple research has highlighted that preschool teachers face numerous barriers in recognising and referring these children for further evaluation (25-27). The challenges can range from personal characteristics of the preschool teachers such as their knowledge, attitude, feelings, skills, and perceptions of children with $\operatorname{ASD}(25,27)$, concerns about their detection ability $(24)$, lack of motivation to identify and refer ASD children (28), low perception of self-efficacy among teachers for special service, and lastly, resource limitation that could influence their referral decisions (27). According to published studies, preschool teachers' abilities to identify and refer students with developmental impairments are limited $(29,30)$ due to a lack of understanding and abilities in dealing with challenging behaviour in children as a result of limited training in this area (31). Therefore, preschool teachers' knowledge and skills in recognising challenging behaviours in children influence their eventual decision to identify and refer children (32-35). In addition, internalising symptoms of ASD are less observable than externalising concerns among children in a class and therefore, less likely to get attention from teachers and the community (36). In comparison, children who disturb the class or learning environment show more visible educational and behavioural problems. Thus, they are more likely to receive services than those who portray less evident or disruptive difficulties (37). Another study found that despite the high frequency of ASD, these disorders are frequently diagnosed late due to the lack of overt or apparent signs such as disrupting class or breaking school regulations. (38). Other challenges can emerge in the form of environmental factors such as the cultural stigma surrounding ASD diagnosis (39). Besides, some teachers do not want to overload the school counsellors with their doubts about a child's disorder (28). Most of the school counsellors are already overloaded with assessment and often lack time for follow-up counselling or intervention (33). In view of these issues, the existing gaps in addressing the challenges surrounding the identification of children with ASD must be explored.

\section{Q5: What is the gap in preschool teachers' identification of children with ASD?}


To date, the factors that influence the early detection of ASD remain under-explored in the literature. As a result of the knowledge gap, there is a lack of guidance on how to successfully implement early screening processes across different populations and cultures (1). Some research has also indicated limited investigation on the actual hurdles of the early detection and referral decision-making process (40). In Yemen, children with ASD often receive a late diagnosis $(41,42)$ that subsequently cast a negative impact on their development. Therefore, preschool teachers in Yemen need to be educated in childhood developmental disorders. An educational module to identify children with ASD through the knowledgebelief-self-efficacy cycle can strengthen the ability of preschool teachers to identify children with ASD. This brings on the final question on the purpose of this research.

\section{Q6: What is the aim of the current study?}

The current study aims to address the needs and unmet needs of preschool teachers for them to identify children with ASD. The findings will fill up a significant gap in the literature regarding early detection of ASD. However, due to the lack of evidence, it is impossible to predict what is the most effective, acceptable, and feasible solution in terms of logistics and practicality. Therefore, a feasibility study is required to determine the applicability and acceptability of the intervention before undertaking a bigger trial in the future.

This proposal outlines the steps involved in conducting a feasibility study for a brief educational module entitled 'Educational Module of Autism Spectrum Disorder (EMASD)' for preschool teachers to identify children with ASD. This protocol aims to evaluate the feasibility and effectiveness of an educational module grounded in the social cognitive theory SCT and health belief model HBM for ASD identification based on preschool teachers' knowledge, beliefs, identifications skills, and self-efficacy. In addition, the study aims to explore the extent of improvement in preschool teacher's identification skills to identify children with ASD following the EMASD.

Preschool teachers in the experimental group are expected to obtain the following benefits as shown in the comparison between the baseline and two-month assessment:

1. An increase in their ASD knowledge scores,

2. An improvement in their ASD beliefs (perceived barriers),

3. An enhancement in their self-efficacy to identify children with ASD.

\section{Materials And Methods}

\subsection{Design}

The current study uses a pragmatic paradigm. It is a convergent parallel mixed study to evaluate the influence of the EMASD by applying both qualitative and quantitative methods to enrich the study findings. The parallel randomised controlled trial (P-RCT) will compare changes in outcomes of interest among preschool teachers allocated to the EMASD experimental group against preschool teachers 
allocated to a control group (no intervention). The data collection involves obtaining quantitative data via questionnaire and qualitative data via open-ended questions. The quantitative and qualitative data findings will be examined separately before contributing to the final interpretation (Fig. 1). The protocol will be reported based on the Standard Protocol Items Recommendations for Interventional Trials (SPIRIT) checklist (Supplementary File 1).

\subsection{Research Participants}

The current study will be based in the province of Taiz, Yemen. There are 125 government schools and 230 private schools in the province. Preschool teachers from these schools will be recruited. The study will be promoted on the Teachers' Qualification Training Course website of the Ministry of Education. The principals of all the schools will also be contacted formally via emails to obtain their approvals. Before the pre-test assessment, all the participants must provide informed consent digitally.

\subsubsection{Selection Criteria}

The sampling unit of this study is a teacher randomly selected from the schools in Taiz based on the following inclusion and exclusion criteria:

\section{Inclusion Criteria}

The inclusion criteria for schools and teachers are:

i. School should be kindergarten, preschool, or primary schools.

ii. Schools located in Taiz.

iii. Schools that agree to participate in the study.

iv. Teachers who are teaching at the kindergarten, preschool, or primary stage.

vi. Teachers aged $20-40$ years old.

vii. Teachers who sign a consent form to participate in the study.

viii. Teachers with at least a high school level of education.

\section{Exclusion Criteria}

The exclusion criteria are:

i. School location is not in Taiz.

ii. Elementary and high schools.

iii. Teachers who will retire during the study period. 
iv. Teachers who teach in elementary and high schools.

v. Teachers with lower than high school education levels.

\subsection{Sample size}

As a feasibility study, this current study is not powered to assess statistical significance. The sample size for this feasibility study is estimated to be around 100 (50 per group) for the experimental group (EG) and control group (CG) respectively. This number is considered to be appropriate for the study objectives and compatible with recommendations for behavioural intervention in this population (43). The Lemeshow equation will be employed to detect the sample size of the experimental and control groups. Notably, this equation is the most widely used approach to compare two groups of equal size and to identify the intervention effect on the outcome for pre-post studies (44). Furthermore, the Lemeshow equation can be used to examine any significant difference between the two population means whether from the same sample of subjects or matched-pair samples. In this study, this equation will be used to assess the two correlated means of EG and CG. As indicated by a study (43), the sufficient sample size calculation for randomised controlled trial (RCT) was based on a (error sort I, $a=0.05$ ), $\beta$ (error sort II, $\beta=0.20$ ), $p$ (level of knowledge in ASD among preschool teachers) (43), and d2 (contrast to be recognised amongst experimental and control groups) (45).

$$
n=\frac{2 \sigma^{2}\left(\boldsymbol{Z}_{1-\boldsymbol{\alpha}}+\boldsymbol{Z}_{1-\boldsymbol{\beta}}\right)^{2}}{\left(\boldsymbol{M}_{1}-\boldsymbol{M}_{2}\right)^{2}}
$$

To determine a suitable sample size adjustment for clustering, standard sample size estimates for individually randomised designs will be calculated first before being inflated by the design effect $(43,46)$.

\subsection{Randomisation and blinding}

After completing the pre-test assessment, all participants who are qualified to participate will be stratified depending on their position and score to ensure a balance between the EG and CG. An impartial researcher will randomly assign participants to either EG or CG using computer-generated allocation, i.e. JavaScript's Math Random Number Generator (hedges.name) (47). As the EMASD intervention will be provided by the researchers, double-blinding of group allocation is not possible. Figure 2 depicts the recruitment procedure. To ensure allocation concealment, each cluster will receive a randomly generated treatment allocation unique code within a serially numbered sealed opaque envelope. The research assistant distributes the sealed opaque envelopes to all the participating schools. Later, the participants will open the envelopes and be assigned to EG or CG according to their unique codes. The software will also categorise EG and CG based on the list of codes. Finally, an equal number of participants will be assigned to the EG and CG. Participants in the CG will continue with the standard teaching qualification course at the Ministry of Education. To assess potential preliminary differences between the two groups, measurements will be performed at Week 10 after the intervention period and again, four weeks after the 
post-test. Following the study completion, the participants in the CG will also receive an information pack on the relevant information and activities related to EMASD.

\subsection{Education Module of Autism Spectrum Disorder (EMASD) Intervention}

EMASD can be used to help preschool teachers identifying children suspected with ASD in normal schools. Therefore, the educational sessions in EMASD are designed based on the ADDIE model and two main theories, namely the Social Cognitive Theory (SCT) in triadic reciprocal determination (behavioural, personal, and environmental factors) and the Health Belief Module (HBM) to change the preschool teachers' belief towards ASD. Both theories are used to indicates the methods to dispel misbeliefs surrounding ASD. Furthermore, EMASD is also developed based on the ADDIE (Analysis-DesignDevelopment-Implement-Evaluation) model (Supplementary file 2). Walter Dick (48) emphasised that any instructional design requires the use of a system to analyse the problems and identify learning objectives before a strategic plan can be established to solve teaching problems, test solutions, evaluate the results and revise the programme. Among the many systematic instructional design models available in the literature, the ADDIE model is the commonly used model. For more details of the theoretical framework development, please see 10.3390/brainsci10030165.

The EMASD consists of 10 sessions that cover different aspects including i. Cognitive (Knowledge: Definition based on DSM5, symptoms, types, causes, prevalence, and the difference between ASD symptoms and other disorders); ii. Beliefs (Emotional: Social misbelief, religious belief, and the correction of the belief about ASD); iii. Identification skills (Motor-behaviour: report writing, observation, and recording skills; iv. Self-efficacy (Emotional: Preschool teachers' responsibility in the identification of ASD and discussion with parents regarding the referral decision). Table 1 outlines the components in EMASD.

The EG will consist of four groups with approximately 10 to 20 teachers respectively. The intervention module will be organised based on the agreement and consensus of the participants. The session will be arranged flexibly based on the schedules of the participants. In addition, a two-hour booster session will be provided to reinforce the intervention and for the participants to discuss further issues related to ASD that will promote further referral services.

Furthermore, the intervention will include activities such as group discussions, brainstorming, short video viewing, exercises, and sharing of teachers' and parents' experiences to enhance early detection and referral. Besides, the intervention will also be outlined in two booklets for trainers and teachers. The intervention will be performed by the first author with the support of the school counsellor. During the intervention period, a WhatsApp group that contains only the EG participants will be created to support the intervention and to boost retention rates. The group will be moderated by the lead facilitator. To further enhance the retention rates, weekly reminders will be sent via private messaging to the EG participants.

\subsection{Data collection}


Both qualitative and quantitative data will be collected from both EG and CG. Firstly, the quantitative data will be collected using questionnaires to determine preschool teachers' knowledge, belief, and selfefficacy. Secondly, open-ended questions will be used to evaluate their identification skills after viewing video cases. Both sets of data will be collected three times: pre-test (Week 0), post-test (Week 10), and follow-up test (Week 14) of the EMASD implementation.

\subsubsection{Primary outcome measure (Quantitative data)}

All participants will be asked to answer the pre-test questionnaire before EMASD is introduced to the EG. The post-test assessment will be carried out one month after the intervention using the same questionnaire. All participants will be reminded to provide truthful responses. All the questionnaires are anonymous and labelled with a 3 digit-code, e.g. E-4-15 stands for the experimental group, School No: 4, and Participant No: 15). The unique numbers and the participant's and school's names will be recorded in a different place for the investigators to identify respondents if the needs arise.

Three questionnaires will be used to collect the quantitative data in this study. Specifically, the knowledge questionnaire will measure the preschool teachers' knowledge of ASD while the beliefs questionnaire about ASD will measure the preschool teachers' belief toward ASD. Another questionnaire on self-efficacy will measure the preschool teacher's ability to discuss the condition with the child's parents before suggesting referral to a specialist. Video cases will be used to measure preschool teachers' skills in identifying children with ASD. The details of the instruments are presented in the following subsections below:

\section{- Preschool Teachers' Knowledge of ASD}

Items in this section were from prior ASD knowledge measurements that targeted school teachers and preschool teachers. The ASD knowledge questionnaire (49) served as a foundation for our adapted version due to its prominent use in the literature. Permission to use the questionnaire was obtained from the original authors (See supplementary file3). To meet the study objectives, the items in the questionnaire were divided into four domains (diagnosis/symptoms (24 items), treatment (12 items), aetiology (6 items), and general information (10 items). These items were initially adapted from another knowledge questionnaire (50) before performing item sampling for other knowledge aspects of ASD (49). Following that, the amended questionnaire was distributed to all investigators. The four domains are as follows:

Domain 1 on the knowledge in diagnosis/symptoms of ASD comprises of 18 items to assess knowledge of diagnosis and symptoms of ASD. These items were adapted from previous measures, namely nine items from ASK-Q (51) and nine items from the Autism Knowledge questionnaire ASD (52).

Domain 2 revolves around ASD treatment and it includes 12 items. All these items were adapted from a recent study (53) to measure the preschool teachers' knowledge about ASD treatment, either medical treatment or behavioural therapy. 
Domain 3 of the knowledge questionnaire includes six items to assess preschool teachers' knowledge in the aetiology of ASD. These items were adapted from prior measures, namely three items from ASK-Q (54) and three other items from the Autism Knowledge questionnaire ASD (55).

Domain 4 in the knowledge questionnaire consists of eight items on the general information about the child and people associated with ASD. Seven items were adapted from ASK-Q (50) while one from the Autism Knowledge questionnaire ASD (55).

\section{- Preschool Teachers' Belief in ASD}

Item selection for this section was based on previous ASD beliefs and the stigma measures targeting teachers, preschool teachers, and parents. This questionnaire will be used to assess the preschool teachers' belief in ASD and the children diagnosed with it. The autism questionnaire by Harrison et al. (2017) was used as the foundation. The last aspect of Harrison's questionnaire revolves around stigma. The items were rearranged in this study based on the aspects of religious belief (six items), social belief (seven items), and personal belief (eight items).

Domain 1 indicates religious beliefs that include religion and spiritual traditions commonly associated with health practices observed around the world. This domain comprises five items to assess parents' religious belief toward ASD, with three items were adapted from ASK-Q (Harrison et al., 2017) and three from (50).

Domain 2 assesses social belief towards ASD. This domain comprises seven items, with five items adapted from (55) and two from Harrison et al. (2017).

Domain 3 denotes personal belief, i.e. an individual's common belief system that serves as an explanatory model for disorders such as ASD. This domain comprises eight items of which four items were adapted from al Sharbati (2015) and another four from ASK-Q (55).

\section{- Preschool Teachers' Self-Efficacy of ASD}

There are two domains in this questionnaire. Items from these two domains were adapted from Drusch (2015b) and (50).

Domain 1 evaluates the ability of preschool teachers to express their concerns on the child's delayed development to their parents and to discuss referral to specialists (nine items).

Domain 2 includes seven items that assess the ability of preschool teachers to decide whether to refer children with ASD to intervention services.

\subsubsection{Primary outcome measure (Qualitative data)}

For the qualitative data, the researcher will randomly select a few participants from both EG and CG. The researcher will use video cases to collect the qualitative data. However, the session will not be repeated so 
the researcher will inform the preschool teachers beforehand to determine a suitable time for each teacher. All this work will be conducted within seven days after the pre-test, post-test, and follow-up test. Each participant will not know that they will be shown the video case. The participant can use paper and pencil, or WhatsApp chat to answer. Before watching the video case, the researcher will brief each teacher about her role during the video as follows:

- These are two video cases of a child. Can you watch the video and answer the questions related to each video?

- The videos include two children's behaviour at several locations. Just focus on his behaviour and then answer the questions.

- You have to finish watching the first video and answer the questions before moving on to the second video.

- The videos will be less than 10 minutes.

-There is no correct or incorrect answer as the aim is to measure the ability to observe the behaviour of the child.

The researcher will meet the participants face-to-face to obtain their answers to the video cases individual. For teachers who are not free, they can answer the questions by WhatsApp or email. The qualitative method will be reported based on the Consolidated criteria for reporting qualitative studies (COREQ) (Supplementary file 3).

\section{- Preschool Teachers' Identification Skills}

The researcher will apply a qualitative method to assess preschool teachers' identification skills. The skills of the preschool teachers in identifying children with ASD will be measured based on the video cases. Open-ended questions will be asked after video-viewing. Two 5-minute videos of two children, one with ASD and the other with ADHD, both aged 6-8 years old, will be part of the case study analysis. Participants will watch the interaction of the ASD child in Video 1 (taken from the Centres for Disease Control, USA) with his mother at home, during playing, and during teaching. Meanwhile, the participants will also observe the ADHD child in Video 2 from the National Institute of Mental Health (NIMH) in various settings including class activities, swimming, and lunch.

The participants will then respond to four questions:

- Is the child having any problems? [Yes/No];

- Based on what you've seen in the videos, what kind of disorder did the child have? [Open response];

- What are the reasons for your answer? [Open response];

- Based on what you've seen in the videos, would you recommend a referral service to the child's parents? [Yes/No] 
Previous studies also used this technique to help participants to identify children with $\operatorname{ASD}(50)(55,56)$. These studies show that observing children's behaviour in their natural setting is the most ecologically valid method for assessing them (55). Therefore, it is also a good method to assess preschool teachers' skills and ability to identify children with ASD.

\subsection{Data monitoring and management}

All data for the study will be collected electronically through a secure online survey platform (https://www.google.com/intl/en-GB/forms/about/). After that, the data will be entered into the Statistical Package of Social Sciences (SPSS 25.0 Version). Qualitative data will be collected with pen and paper and analysed manually by the team members without using any software programme. All data will be anonymised and stored electronically at Universiti Putra Malaysia. Data access will be passwordprotected. The final dataset will be accessible only to the research team.

\section{Ethical considerations}

This study conforms to the principles of the Declaration and Research Ethics Committee at University Putra Malaysia (UPM), with a reference number of UPM ITNCPIIRMC \JKEUPM\1.4.18.2 (JKEUPM). In addition, informed consent will be obtained from preschool teachers before their recruitment. They will be informed that their participation in the study is voluntary and all information will be anonymised. Likewise, they can withdraw from this research without giving any reason anytime. Moreover, the researcher will reassure them that all the information provided will remain private and confidential. In addition, the researcher will also ask the participants if they agree/do not agree for the images/photos/video recordings/voice recordings related to their activities to be used in any form of publication or presentation.

\section{Outcome measures}

Relevant feasibility and acceptability criteria will be used to determine whether a formal RCT is necessary to continue the evaluation of this intervention. The feasibility of the intervention will be assessed using a combination of quantitative and qualitative methods. The following are the outcome measures for determining feasibility and acceptability:

1. Rate of recruitment, including willingness to be randomly assigned.

2. Any adverse effects that occur throughout the intervention period.

3. Descriptive analysis of missing data will be used to assess the appropriateness of the data collection measures and procedures.

4. The rates and reasons for drop-out will be tracked to establish whether the intervention is acceptable to participants.

5. During pre-test and at Week 9, participants from the EG will be invited to a qualitative interview to assess the acceptability of EMASD and the outcome measures. The focus group interview will be audio-recorded and analysed. The content, organisation, format, and mode of delivery of the 
intervention will be evaluated using a topic list. quality comments from participants about their EMASD experience should indicate whether a larger trial is feasible.

\subsection{Data Analysis}

Quantitative data will be analysed using SPSS 25.0 Version. Data entry and data cleaning will be performed. Any outliers will be identified using skewness and kurtosis scores, including distribution plots. Generally, data will be assessed to determine the extent and pattern of the missing data. Categorical variables such as age and educational level will be described using frequencies and proportions. The pretest measurement for the outcomes variables (KBSE) will be outlined as mean, standard deviation, and range. Data normality will be checked using skewness and Q-Q plot. Chi-square test will be performed to determine the association between categorical data, for example, the comparison between groups before implementing the intervention. In addition, General Linear Model (GLM) repeated measure will be conducted to check for any significant difference in the ASD knowledge, belief, and self-efficacy (KBSE) scores between study groups at different times of the study. The repeated measures will detect the differences in the continuous data for between-group and within-group comparison. Finally, to compare the KBSE scores within and between study groups after controlling for age, a two-way Multivariate Analysis of Covariance (MANCOVA) will be used. Statistical significance is set at $p<0.05$.

As for qualitative data, thematic analysis (TA) will be performed. It is a qualitative data analysis method typically used to describe a group of texts, such as interview transcripts. The researcher will study the data carefully for common themes, i.e. subjects, concepts, and patterns of similar repeating meanings. In this study, TA will be used to analyse the participants' responses to the open-ended questions after watching the video case. Since TA is often subjective and relies on the researcher's judgment, it can lead to the risk of missing certain nuances in the data. In this study, the researcher will use an inductive approach that uses the data to determine the common themes among preschool teachers. Therefore, the researcher must reflect carefully on the choices and interpretations of the themes. Then, the emerged themes will be submitted to two other authors to prevent any bias in the thematic choices.

\section{Declarations}

\section{Declarations}

\section{Ethics approval and consent to participate}

This study conforms to the principles of the Declaration and Research Ethics Committee at University Putra Malaysia (UPM), with a reference number of UPMITNCPI\RMC \JKEUPM\1.4.18.2 (JKEUPM). (See supplementary file 4)

\section{Consent for publication}


The informed consent will be obtained from preschool teachers before their recruitment.

\section{Declarations}

\section{Competing interests}

The authors declare that they have no competing interests.

\section{Funding}

We were supported by a Yemeni Ministry of higher education (YMHE), Taiz University. kindergarten department.

\section{References}

1. Øien RA, Vivanti G, Robins DL. Editorial SI. Early Identification in Autism Spectrum Disorders: The Present and Future, and Advances in Early Identification. J Autism Dev Disord. 2021;51(3):763-8.

2. Vivanti G, Dissanayake C. Outcome for children receiving the Early Start Denver Model before and after 48 months. J Autism Dev Disord. 2016;46(7):2441-9.

3. Sacrey LA, Zwaigenbaum L, Bryson S, Brian J, Smith IM, Roberts W, et al. Can parents' concerns predict autism spectrum disorder? A prospective study of high-risk siblings from 6 to 36 months of age. J Am Acad Child Adolesc Psychiatry. 2015;54(6):470-8.

4. Zwaigenbaum L, Bauman ML, Choueiri R, Kasari C, Carter A, Granpeesheh D, et al. Early intervention for children with autism spectrum disorder under 3 years of age: recommendations for practice and research. Pediatrics. 2015;136(Supplement 1):60-81.

5. Constantino JN, Abbacchi AM, Saulnier C, Klaiman C, Mandell DS, Zhang Y, et al. Timing of the diagnosis of autism in African American children. Pediatrics. 2020;146(3).

6. Jacobson JW, Mulick JA, Green G. Cost-benefit estimates for early intensive behavioral intervention for young children with autism-general model and single state case. Behavioral Interventions: Theory \& Practice in Residential \& Community-Based Clinical Programs. 1998;13(4):201 - 26.

7. Griffith SF, Maynard D-MB, Bagner DM. Barbadian teachers' identification of social-emotional, behavioral, and learning challenges in young children. International Journal of School \& Educational Psychology. 2020:1-17.

8. Drusch SJ. The Early Identification of Autism Spectrum Disorder in Preschool Settings [Master of social work ]: Catherine University 2015.

9. Jonsdottir SL, Saemundsen E, Gudmundsdottir S, Haraldsdottir GS, Palsdottir AH, Rafnsson V. Implementing an early detection program for autism in primary healthcare: Screening, education of healthcare professionals, referrals for diagnostic evaluation, and early intervention. Research in Autism Spectrum Disorders. 2020;77:101616. 
10. Baio J, Wiggins L, Christensen DL, Maenner MJ, Daniels J, Warren Z, et al. Prevalence of autism spectrum disorder among children aged 8 years-autism and developmental disabilities monitoring network, 11 sites, United States, 2014. MMWR Surveillance Summaries. 2018;67(6):1.

11. Brett D, Warnell F, McConachie H, Parr JR. Factors affecting age at ASD diagnosis in UK: no evidence that diagnosis age has decreased between 2004 and 2014. J Autism Dev Disord. 2016;46(6):197484.

12. Taresh SM, Ahmad NA, Roslan S, Ma'rof AM, editors. Knowledge in Autism Spectrum Disorder (ASD) among Pre-School Teachers in Yemen. 3rd International Conference on Special Education (ICSE 2019); 2019: Atlantis Press.

13. Desta M, Deyessa N, Fish I, Maxwell B, Zerihun T, Levine S,. Mind. et al. Empowering Preschool Teachers to Identify Mental Health Problems: A Task-Sharing Intervention in Ethiopia. Brain Education. 2017;11(1):32-42.

14. Elliott SN, Huai N, Roach AT. Universal and early screening for educational difficulties: Current and future approaches. J Sch Psychol. 2007;45(2):137-61.

15. Greenberg MT, Domitrovich C, Bumbarger B. The prevention of mental disorders in school-aged children: Current state of the field. Prevention treatment. 2001;4(1):1a.

16. Luk S-L, Leung PW-L, Bacon-Shone J, Lieh-Mak F. The structure and prevalence of behavioral problems in Hong Kong preschool children. J Abnorm Child Psychol. 1991;19(2):219-32.

17. Rones M, Hoagwood K. School-based mental health services: A research review. Clin Child Fam Psychol Rev. 2000;3(4):223-41.

18. Leblanc L, Richardson W, Burns KA. Autism Spectrum Disorder and the Inclusive Classroom:Effective Training to Enhance Knowledge of ASD and Evidence-Based Practices. Teacher Education Special Education. 2009;32(2):166-79.

19. Neely-Barnes SL, Hall HR, Roberts RJ, Graff JC. Parenting a Child With an Autism Spectrum Disorder: Public Perceptions and Parental Conceptualizations. Journal of Family Social Work. 2011;14(3):208-25.

20. Stone WL, Rosenbaum JL. A comparison of teacher and parent views of autism. Journal of Autism Developmental disorders. 1988;18(3):403-14.

21. Barrie D. Factors that influence parents toward early diagnosis of autism spectrum disorder [Master of Arts]. Ontario: canada Faculty of Nursing, University of Windsor; 2010.

22. Dereu M, Raymaekers R, Warreyn P, Schietecatte I, Meirsschaut M, Roeyers H. Can child care workers contribute to the early detection of autism spectrum disorders? A comparison between screening instruments with child care workers versus parents as informants. J Autism Dev Disord. 2012;42(5):781-96.

23. Johnson P, Porter K, McPherson I. Autism knowledge among pre-service teachers specialized in children birth through age five: Implications for health education. American Journal of Health Education. 2012;43(5):279-87. 
24. Peters S, Miske SJ, Johnstone C, Harris DP, Wolbers KA, Trotman A, et al. Achieving Inclusion: Transforming the education system of Trinidad and Tobago. Final Report. Minnesota: Miske Witt and Associates; 2008.

25. Biasotti N. he Impact of Professional Development Training in Autism and Experience on Teachers' Self Efficacy. Walden Dissertations and Doctoral Studies Collection at ScholarWorks: Walden University; 2013.

26. Rothì DM, Leavey G, Best R. On the front-line: Teachers as active observers of pupils' mental health. Teaching Teacher Education. 2008;24(5):1217-31.

27. Able H. Preschool Teachers' Perceptions of Factors Influencing their Referral Decisions for Young Children with Severe behavior Problems DISSERTATION. The University of North Carolina: Chapel Hill, NC, USA. 2012.

28. Ensimau NK, editor Teacher's Ability in Identifying Pupils With Disability in Classroom, Kapit, Sarawak. 3rd International Conference on Special Education (ICSE 2019); 2019: Atlantis Press.

29. Bradshaw CP, Buckley JA, lalongo NSJSPQ. School-based service utilization among urban children with early onset educational and mental health problems: The squeaky wheel phenomenon. 2008;23(2):169.

30. Splett JW, Garzona M, Gibson N, Wojtalewicz D, Raborn A, Reinke WM. Teacher Recognition, Concern, and Referral of Children's Internalizing and Externalizing Behavior Problems. School Mental Health. 2018;11(2):228-39.

31. Alexander JL, Ayres KM, Smith KA. Training Teachers in Evidence-Based Practice for Individuals With Autism Spectrum Disorder:A Review of the Literature. Teacher Education Special Education. 2015;38(1):13-27.

32. Dunlap G, Strain PS, Fox L, Carta JJ, Conroy M, Smith BJ, et al. Prevention and intervention with young children's challenging behavior: Perspectives regarding current knowledge. Behavioral Disorders. 2006;32(1):29-45.

33. Fantuzzo J, Stoltzfus J, Lutz MN, Hamlet H, Balraj V, Turner C, et al. An evaluation of the special needs referral process for low-income preschool children with emotional and behavioral problems. Early Childhood Research Quarterly. 1999;14(4):465-82.

34. Fox L, Smith BJ. Promoting Social, Emotional and Behavioral Outcomes of Young Children Served under IDEA. Issue Brief. Technical Assistance Center on Social Emotional Intervention for Young Children; 2007.

35. Lee J-y. Predictors of teachers' intention to refer students with ADHD to mental health professionals: Comparison of US and South Korea. School Psychology Quarterly. 2014;29(4):385.

36. Hinchliffe KJ, Campbell MA. Tipping Points: Teachers' Reported Reasons for Referring Primary School Children for Excessive Anxiety. Journal of Psychologists Counsellors in Schools. 2015;26(1):84-99.

37. Bell ML, McKenzie JE. Designing psycho-oncology randomised trials and cluster randomised trials: variance components and intra-cluster correlation of commonly used psychosocial measures. 
Psycho-oncology. 2013;22(8):1738-47.

38. Splett JW, Garzona M, Gibson N, Wojtalewicz D, Raborn A, Reinke WM. Teacher recognition, concern, and referral of children's internalizing and externalizing behavior problems. School mental health. 2019;11(2):228-39.

39. Reinke WM, Stormont M, Herman KC, Puri R, Goel N. Supporting children's mental health in schools: Teacher perceptions of needs, roles, and barriers. School Psychology Quarterly. 2011;26(1):1-13.

40. Rosenbaum M, Gabrielsen TP. Decision factors for community providers when referring very young children for autism evaluation. Research in Autism Spectrum Disorders. 2019;57:87-96.

41. Alyahri A, Goodman R. The prevalence of DSM-IV psychiatric disorders among 7-10 year old Yemeni schoolchildren. Soc Psychiatry Psychiatr Epidemiol. 2008;43(3):224-30.

42. Taresh SM, Ahmad NA, Roslan S, Ma'rof AM. Preschool Teachers' Beliefs towards Children with Autism Spectrum Disorder (ASD) in Yemen. Children. 2020;7(10):170.

43. Lwanga SK, Lemeshow S, Organization WH. Sample size determination in health studies: a practical manual. World Health Organization; 1991.

44. Ary D, Jacobs LC, Irvine CKS, Walker D. Introduction to research in education. Business \& Economics > Education ed. 10, editor: Cengage Learning; 2018. 720 pages $\mathrm{p}$.

45. Perels F, Merget-Kullmann M, Wende M, Schmitz B, Buchbinder C. Improving self-regulated learning of preschool children: evaluation of training for kindergarten teachers. Br J Educ Psychol. 2009;79(Pt 2):311-27.

46. Campbell DT, Stanley JC. Experimental and quasi-experimental designs for research. Ravenio Books; 2015.

47. Picker RNG.

48. Walter Dick LC, James O. Carey. The Systematic The Systematic Design of Instruction Design of Instruction. 8 ed. New York: Allyn \& Bacon; 2014.

49. Chambers NJ, Wetherby AM, Stronach ST, Njongwe N, Kauchali S, Grinker RR. Early detection of autism spectrum disorder in young isiZulu-speaking children in South Africa. Autism. 2017;21(5):518-26.

50. Harrison AJ, Bradshaw LP, Naqvi NC, Paff ML, Campbell JM. Development and Psychometric Evaluation of the Autism Stigma and Knowledge Questionnaire (ASK-Q). J Autism Dev Disord. 2017;47(10):3281-95.

51. Zwaigenbaum L, Bryson S, Lord C, Rogers S, Carter A, Carver L, et al. Clinical assessment and management of toddlers with suspected autism spectrum disorder: insights from studies of high-risk infants. Pediatrics. 2009;123(5):1383-91.

52. Rivard M, Morin M, Mercier C, Terroux A, Mello C, Lépine A. Social Validity of a Training and Coaching Program for Parents of Children With Autism Spectrum Disorder on a Waiting List for Early Behavioral Intervention. J Child Fam Stud. 2016;26(3):877-87. 
53. Ben-Sasson A, Atun-Einy O, Yahav-Jonas G, Lev-On S, Gev T. Training Physical Therapists in Early ASD Screening. J Autism Dev Disord. 2018;48(11):3926-38.

54. Harrison AJ, Slane MM, Hoang L, Campbell JM. An international review of autism knowledge assessment measures. Autism. 2017;21(3):262-75.

55. Al-Sharbati MM, Al-Farsi YM, Ouhtit A, Waly MI, Al-Shafaee M, Al-Farsi O, et al. Awareness about autism among school teachers in Oman: a cross-sectional study. Autism. 2015;19(1):6-13.

56. Gilligan P. The Challenge of Cultural Explanations and Religious Requirements for Children with Autistic Spectrum Conditions: South Asian Muslim Parents in Bradford, England. Journal of Religion Disability Health. 2013;17(4):393-408.

57. Sallows GO, Graupner TD. Intensive behavioral treatment for children with autism: Four-year outcome and predictors. American journal on mental retardation. 2005;110(6):417-38.

58. Harris SL, Handleman JS. Age and IQ at intake as predictors of placement for young children with autism: A four-to six-year follow-up. J Autism Dev Disord. 2000;30(2):137-42.

59. Saggu RK. Parental perceptions of the diagnostic process for autism spectrum disorder in British Columbia 2015.

60. Gustafson KL, Branch RM. What is instructional design. Trends issues in instructional design technology. 2002;2:10-6.

\section{Discussion And Conclusion}

The increasing prevalence of ASD among children warrants early detection of any aberrant development by preschool teachers to ensure prompt referral to specialists $(57,58)$. On a similar note, more research is needed to generate evidence-based guidelines to better identify children with ASD so that they can receive the necessary intervention (59). As emphasised by Robin (2021), factors influencing early identification of children with ASD remain understudied in the literature, thus affecting early diagnosis of the condition. In view of this research gap, this study focuses on the development of an educational module to assist preschool teachers in identifying autistic children at an early stage. Such efforts will benefit children with ASD, preschool teachers, and parents in developing countries such as Yemen.

Theoretically, this study aims to develop an educational module on autism spectrum disorder (EMASD) for preschool teachers. The development of the educational module follows organised and robust steps to ensure the validity and strength of the module. Two theories will be used, including SCT and HBM. The SCT focuses on shaping and modifying individuals' behaviour. Thus, this study also aims to determine the effectiveness of the SCT in training preschool teachers to identify children with ASD. However, SCT concentrates only on the individuals' cognitive and behavioural aspects, thus neglecting the emotional aspect. Therefore, another theory, i.e. the HBM, will also be incorporated to assess the emotional aspect. On top of that, the module will be strengthened by the ADDIE model to achieve a higher level of effectiveness. Therefore, this study will confer significant theoretical contributions to the literature body on teachers' training in the detection of childhood developmental disorders. More importantly, the current 
study investigates several independent variables in relation to the early detection of child disorders by preschool teachers. The findings can complement previous studies that mostly lacked the actual implementation of interventions.

Furthermore, the current study also has practical significance. Firstly, Yemen is considered one of the most impoverished countries according to a World Bank report in 2016. Even though the prevalence of ASD among children is estimated at a ratio of 1:50 children globally, confirmed cases reported in the Arabic countries remain low. In addition, there is also a scarcity of published Yemeni studies on children with developmental disorders, as confirmed by a review study (Hussein \& Taha, 2013). Therefore, this study will be able to generate important primary data concerning Yemeni preschool teachers' knowledge, beliefs, and self-efficacy of ASD. These baseline data will also benefit other like-minded researchers.

Secondly, by researching the issue of ASD among children, the local situation in Yemen can be compared with global data. The findings will also shed light on the best ways to prevent children with ASD from being mistakenly diagnosed with other behavioural disorders. ASD children need special care and highly trained teachers to help educate them properly. Thus, early detection is vital to ensure prompt diagnosis so that practical solutions can be implemented to improve the condition.

Thirdly, preschool teachers play a fundamental role in the learning process. Thus, they are well-positioned in the early detection of children with ASD and parental education. The study can lead to an increased awareness of ASD among preschool schools teachers, as well as providing them with suitable training on the detection and management of children with ASD. Increased awareness will likely improve their knowledge, ideas, and beliefs about children with ASD, apart from enhancing their skills in identifying these children at an early stage.

Next, we also hope to spread awareness among stressed-out parents and other community members with misunderstanding about children with ASD. Apart from the support from public organisations, parents with ASD children also require specific training on how to recognise and manage such disorders to ensure better behavioural outcomes. Similarly, preschool teachers play a vital role in educating and motivating the future generation, thus it is very important for them to be equipped with better health education regarding childhood issues. In general, this research will directly benefit preschool teach preschoolers, families, and community members, as well as provide vital information to the researchers, policymakers, educators, and healthcare workers to produce beneficial interventions for ASD children in schools.

Overall, there are several strengths to this study. Specifically, the RCT design is considered a gold standard for interventional research. In addition, this study will incorporate a qualitative approach to acquire a realistic portrayal of the ability of preschool teachers to implement the knowledge. Another strength of this study is the translated and validated version of the questionnaires by Harrison (2017), used to determine the knowledge and beliefs of the different aspects of ASD among teachers. Furthermore, the educational module will be customised according to the context of this study based on the theories of SCT, HBM, and the ADDIE model. As mentioned before, Gustafson and Branch 
(60) introduced six features within the systematic ADDIE model that can contribute to the feasibility of this module to be used among the preschool teachers in this study.

ASD is one of the most common types of childhood disorders, thus it warrants the attention of policymakers in the education and health sectors. An in-depth understanding of ASD can provide useful information in the planning and development of an ASD detection policy at the organisational level. In short, an evaluation of the ASD module, including the ideal age to commence detection is urgently needed to reduce delayed or wrong diagnosis of ASD.

\section{Harms}

We do not anticipate any harms to preschool teachers as a result of participating in this study

\section{Declarations}

\section{Ethics approval and consent to participate}

This study conforms to the principles of the Declaration and Research Ethics Committee at University Putra Malaysia (UPM), with a reference number of UPM\TNCPI\RMC \JKEUPM\1.4.18.2 (JKEUPM). (See supplementary file 4)

\section{Consent for publication}

The informed consent will be obtained from preschool teachers before their recruitment.

\section{Availability of data and materials}

Trial data can be obtained upon request from the corresponding author

\section{Competing interests}

The authors declare that they have no competing interests.

\section{Funding}

We were supported by a Yemeni Ministry of higher education (YMHE), Taiz University. kindergarten department.

\section{Authors' contributions}

SMTand SMZ conceived the study design. NAA, SR, and AMM refined the study design. SMTand SMZ drafted the initial manuscript for submission. All authors reviewed and approved the final manuscript before submission.

\section{Acknowledgements}


Authors details

Frist page

\section{References}

1. Øien RA, Vivanti G, Robins DL. Editorial SI: Early Identification in Autism Spectrum Disorders: The Present and Future, and Advances in Early Identification. Journal of Autism and Developmental Disorders. 2021;51(3):763-8.

2. Vivanti G, Dissanayake C. Outcome for children receiving the Early Start Denver Model before and after 48 months. Journal of autism and developmental disorders. 2016;46(7):2441-9.

3. Sacrey LA, Zwaigenbaum L, Bryson S, Brian J, Smith IM, Roberts W, et al. Can parents' concerns predict autism spectrum disorder? A prospective study of high-risk siblings from 6 to 36 months of age. J Am Acad Child Adolesc Psychiatry. 2015;54(6):470-8.

4. Zwaigenbaum L, Bauman ML, Choueiri R, Kasari C, Carter A, Granpeesheh D, et al. Early intervention for children with autism spectrum disorder under 3 years of age: recommendations for practice and research. Pediatrics. 2015;136(Supplement 1):S60-S81.

5. Constantino JN, Abbacchi AM, Saulnier C, Klaiman C, Mandell DS, Zhang Y, et al. Timing of the diagnosis of autism in African American children. Pediatrics. 2020;146(3).

6. Jacobson JW, Mulick JA, Green G. Cost-benefit estimates for early intensive behavioral intervention for young children with autism-general model and single state case. Behavioral Interventions: Theory \& Practice in Residential \& Community-Based Clinical Programs. 1998;13(4):201-26.

7. Griffith SF, Maynard D-MB, Bagner DM. Barbadian teachers' identification of social-emotional, behavioral, and learning challenges in young children. International Journal of School \& Educational Psychology. 2020:1-17.

8. Drusch SJ. The Early Identification of Autism Spectrum Disorder in Preschool Settings [Master of social work ]: Catherine University 2015.

9. Jonsdottir SL, Saemundsen E, Gudmundsdottir S, Haraldsdottir GS, Palsdottir AH, Rafnsson V. Implementing an early detection program for autism in primary healthcare: Screening, education of healthcare professionals, referrals for diagnostic evaluation, and early intervention. Research in Autism Spectrum Disorders. 2020;77:101616.

10. Baio J, Wiggins L, Christensen DL, Maenner MJ, Daniels J, Warren Z, et al. Prevalence of autism spectrum disorder among children aged 8 years-autism and developmental disabilities monitoring 
network, 11 sites, United States, 2014. MMWR Surveillance Summaries. 2018;67(6):1.

11. Brett D, Warnell F, McConachie H, Parr JR. Factors affecting age at ASD diagnosis in UK: no evidence that diagnosis age has decreased between 2004 and 2014. Journal of autism and developmental disorders. 2016;46(6):1974-84.

12. Taresh SM, Ahmad NA, Roslan S, Ma'rof AM, editors. Knowledge in Autism Spectrum Disorder (ASD) among Pre-School Teachers in Yemen. 3rd International Conference on Special Education (ICSE 2019); 2019: Atlantis Press.

13. Desta M, Deyessa N, Fish I, Maxwell B, Zerihun T, Levine S, et al. Empowering Preschool Teachers to Identify Mental Health Problems: A Task-Sharing Intervention in Ethiopia. Mind, Brain, and Education. 2017;11(1):32-42.

14. Elliott SN, Huai N, Roach AT. Universal and early screening for educational difficulties: Current and future approaches. Journal of School Psychology. 2007;45(2):137-61.

15. Greenberg MT, Domitrovich C, Bumbarger B. The prevention of mental disorders in school-aged children: Current state of the field. Prevention \& treatment. 2001;4(1):1a.

16. Luk S-L, Leung PW-L, Bacon-Shone J, Lieh-Mak F. The structure and prevalence of behavioral problems in Hong Kong preschool children. Journal of Abnormal Child Psychology. 1991;19(2):219-32.

17. Rones M, Hoagwood K. School-based mental health services: A research review. Clinical child and family psychology review. 2000;3(4):223-41.

18. Leblanc L, Richardson W, Burns KA. Autism Spectrum Disorder and the Inclusive Classroom:Effective Training to Enhance Knowledge of ASD and Evidence-Based Practices. Teacher Education and Special Education. 2009;32(2):166-79.

19. Neely-Barnes SL, Hall HR, Roberts RJ, Graff JC. Parenting a Child With an Autism Spectrum Disorder: Public Perceptions and Parental Conceptualizations. Journal of Family Social Work. 2011;14(3):208-25.

20. Stone WL, Rosenbaum JL. A comparison of teacher and parent views of autism. Journal of Autism and Developmental disorders. 1988;18(3):403-14.

21. Barrie D. Factors that influence parents toward early diagnosis of autism spectrum disorder [Master of Arts]. Ontario, canada Faculty of Nursing, University of Windsor 2010.

22. Dereu M, Raymaekers R, Warreyn P, Schietecatte I, Meirsschaut M, Roeyers H. Can child care workers contribute to the early detection of autism spectrum disorders? A comparison between screening instruments with child care workers versus parents as informants. Journal of autism and developmental disorders. 2012;42(5):781-96. 
23. Johnson P, Porter K, McPherson I. Autism knowledge among pre-service teachers specialized in children birth through age five: Implications for health education. American Journal of Health Education. 2012;43(5):279-87.

24. Peters S, Miske SJ, Johnstone C, Harris DP, Wolbers KA, Trotman A, et al. Achieving Inclusion: Transforming the education system of Trinidad and Tobago. Final Report. Minnesota, USA: Miske Witt and Associates; 2008.

25. Biasotti N. he Impact of Professional Development Training in Autism and Experience on Teachers' Self Efficacy. Walden Dissertations and Doctoral Studies Collection at ScholarWorks: Walden University; 2013.

26. Rothì DM, Leavey G, Best R. On the front-line: Teachers as active observers of pupils' mental health. Teaching and Teacher Education. 2008;24(5):1217-31.

27. Able H. Preschool Teachers' Perceptions of Factors Influencing their Referral Decisions for Young Children with Severe behavior Problems DISSERTATION. The University of North Carolina: Chapel Hill, NC, USA. 2012.

28. Ensimau NK, editor Teacher's Ability in Identifying Pupils With Disability in Classroom, Kapit, Sarawak. 3rd International Conference on Special Education (ICSE 2019); 2019: Atlantis Press.

29. Bradshaw CP, Buckley JA, lalongo NSJSPQ. School-based service utilization among urban children with early onset educational and mental health problems: The squeaky wheel phenomenon. 2008;23(2):169.

30. Splett JW, Garzona M, Gibson N, Wojtalewicz D, Raborn A, Reinke WM. Teacher Recognition, Concern, and Referral of Children's Internalizing and Externalizing Behavior Problems. School Mental Health. 2018;11(2):228-39.

31. Alexander JL, Ayres KM, Smith KA. Training Teachers in Evidence-Based Practice for Individuals With Autism Spectrum Disorder:A Review of the Literature. Teacher Education and Special Education. 2015;38(1):13-27.

32. Dunlap G, Strain PS, Fox L, Carta JJ, Conroy M, Smith BJ, et al. Prevention and intervention with young children's challenging behavior: Perspectives regarding current knowledge. Behavioral Disorders. 2006;32(1):29-45.

33. Fantuzzo J, Stoltzfus J, Lutz MN, Hamlet H, Balraj V, Turner C, et al. An evaluation of the special needs referral process for low-income preschool children with emotional and behavioral problems. Early Childhood Research Quarterly. 1999;14(4):465-82.

34. Fox L, Smith BJ. Promoting Social, Emotional and Behavioral Outcomes of Young Children Served under IDEA. Issue Brief. Technical Assistance Center on Social Emotional Intervention for Young Children. 
2007.

35. Lee J-y. Predictors of teachers' intention to refer students with ADHD to mental health professionals: Comparison of US and South Korea. School Psychology Quarterly. 2014;29(4):385.

36. Hinchliffe KJ, Campbell MA. Tipping Points: Teachers' Reported Reasons for Referring Primary School Children for Excessive Anxiety. Journal of Psychologists and Counsellors in Schools. 2015;26(1):84-99.

37. Bell ML, McKenzie JE. Designing psycho-oncology randomised trials and cluster randomised trials: variance components and intra-cluster correlation of commonly used psychosocial measures. Psychooncology. 2013;22(8):1738-47.

38. Splett JW, Garzona M, Gibson N, Wojtalewicz D, Raborn A, Reinke WM. Teacher recognition, concern, and referral of children's internalizing and externalizing behavior problems. School mental health. 2019;11(2):228-39.

39. Reinke WM, Stormont M, Herman KC, Puri R, Goel N. Supporting children's mental health in schools: Teacher perceptions of needs, roles, and barriers. School Psychology Quarterly. 2011;26(1):1-13.

40. Rosenbaum M, Gabrielsen TP. Decision factors for community providers when referring very young children for autism evaluation. Research in Autism Spectrum Disorders. 2019;57:87-96.

41. Alyahri A, Goodman R. The prevalence of DSM-IV psychiatric disorders among 7-10 year old Yemeni schoolchildren. Soc Psychiatry Psychiatr Epidemiol. 2008;43(3):224-30.

42. Taresh SM, Ahmad NA, Roslan S, Ma'rof AM. Preschool Teachers' Beliefs towards Children with Autism Spectrum Disorder (ASD) in Yemen. Children. 2020;7(10):170.

43. Lwanga SK, Lemeshow S, Organization WH. Sample size determination in health studies: a practical manual: World Health Organization; 1991.

44. Ary D, Jacobs LC, Irvine CKS, Walker D. Introduction to research in education. Business \& Economics > Education ed. 10, editor: Cengage Learning; 2018. 720 pages $p$.

45. Perels F, Merget-Kullmann M, Wende M, Schmitz B, Buchbinder C. Improving self-regulated learning of preschool children: evaluation of training for kindergarten teachers. Br J Educ Psychol. 2009;79(Pt 2):31127.

46. Campbell DT, Stanley JC. Experimental and quasi-experimental designs for research: Ravenio Books; 2015.

47. Picker RNG.

48. Walter Dick LC, James O. Carey. The Systematic The Systematic Design of Instruction Design of Instruction. 8 ed: New York: Allyn \& Bacon; 2014. 
49. Chambers NJ, Wetherby AM, Stronach ST, Njongwe N, Kauchali S, Grinker RR. Early detection of autism spectrum disorder in young isiZulu-speaking children in South Africa. Autism. 2017;21(5):518-26.

50. Harrison AJ, Bradshaw LP, Naqvi NC, Paff ML, Campbell JM. Development and Psychometric Evaluation of the Autism Stigma and Knowledge Questionnaire (ASK-Q). J Autism Dev Disord. 2017;47(10):3281-95.

51. Zwaigenbaum L, Bryson S, Lord C, Rogers S, Carter A, Carver L, et al. Clinical assessment and management of toddlers with suspected autism spectrum disorder: insights from studies of high-risk infants. Pediatrics. 2009;123(5):1383-91.

52. Rivard M, Morin M, Mercier C, Terroux A, Mello C, Lépine A. Social Validity of a Training and Coaching Program for Parents of Children With Autism Spectrum Disorder on a Waiting List for Early Behavioral Intervention. Journal of Child and Family Studies. 2016;26(3):877-87.

53. Ben-Sasson A, Atun-Einy O, Yahav-Jonas G, Lev-On S, Gev T. Training Physical Therapists in Early ASD Screening. J Autism Dev Disord. 2018;48(11):3926-38.

54. Harrison AJ, Slane MM, Hoang L, Campbell JM. An international review of autism knowledge assessment measures. Autism. 2017;21(3):262-75.

55. Al-Sharbati MM, Al-Farsi YM, Ouhtit A, Waly MI, Al-Shafaee M, Al-Farsi O, et al. Awareness about autism among school teachers in Oman: a cross-sectional study. Autism. 2015;19(1):6-13.

56. Gilligan P. The Challenge of Cultural Explanations and Religious Requirements for Children with Autistic Spectrum Conditions: South Asian Muslim Parents in Bradford, England. Journal of Religion, Disability \& Health. 2013;17(4):393-408.

57. Sallows GO, Graupner TD. Intensive behavioral treatment for children with autism: Four-year outcome and predictors. American journal on mental retardation. 2005;110(6):417-38.

58. Harris SL, Handleman JS. Age and IQ at intake as predictors of placement for young children with autism: A four-to six-year follow-up. Journal of autism and developmental disorders. 2000;30(2):137-42.

59. Saggu RK. Parental perceptions of the diagnostic process for autism spectrum disorder in British Columbia 2015.

60. Gustafson KL, Branch RM. What is instructional design. Trends and issues in instructional design and technology. 2002;2:10-6.

\section{Tables}

Table 1. Components of EMASD 


\begin{tabular}{|c|c|c|c|c|}
\hline & Unite & Objectives & Sessions & Activities \\
\hline 1 & Knowledge & $\begin{array}{l}\text { Help PSTs to understand. } \\
\text { The defiance concept of ASD. } \\
\text { Types of ASD. } \\
\text { Symptoms of children with ASD. } \\
\text { Causes of ASD. } \\
\text { The Prevalence of ASD. } \\
\text { Early signs of ASD. }\end{array}$ & 3 & $\begin{array}{l}\text { Group } \\
\text { Working } \\
\text { Videos } \\
\text { Paper Sheet } \\
\text { Review } \\
\text { Work Sheet } \\
\text { Brainstorm- }\end{array}$ \\
\hline 2 & Beliefs & $\begin{array}{l}\text { Help PSTs to discuss } \\
\text { Incorrect (religion-social-personal) } \\
\text { belief. } \\
\text { Correct the beliefs. }\end{array}$ & 2 & $\begin{array}{l}\text { Home } \\
\text { Assignment } \\
\text { Activity }\end{array}$ \\
\hline 3 & Identification Skills & $\begin{array}{l}\text { Help PSTs to be able to } \\
\text { Understand their role in an early } \\
\text { diagnosis. } \\
\text { Differences between ASD and other } \\
\text { disorders. } \\
\text { Observe the suspected child in the } \\
\text { class. } \\
\text { Record suspected child behaviour. } \\
\text { Write a report on child behaviour. }\end{array}$ & 3 & $\begin{array}{l}\text { Video Case } \\
\text { Role Play }\end{array}$ \\
\hline 4 & $\begin{array}{l}\text { Self-efficacy to identify } \\
\text { children with ASD }\end{array}$ & $\begin{array}{l}\text { Help PSTs to be able to } \\
\text { Discuss with parents or psychologist } \\
\text { about their concern. } \\
\text { Suggest for parents to refer a child to } \\
\text { a specialist. }\end{array}$ & 2 & \\
\hline
\end{tabular}

\section{Figures}




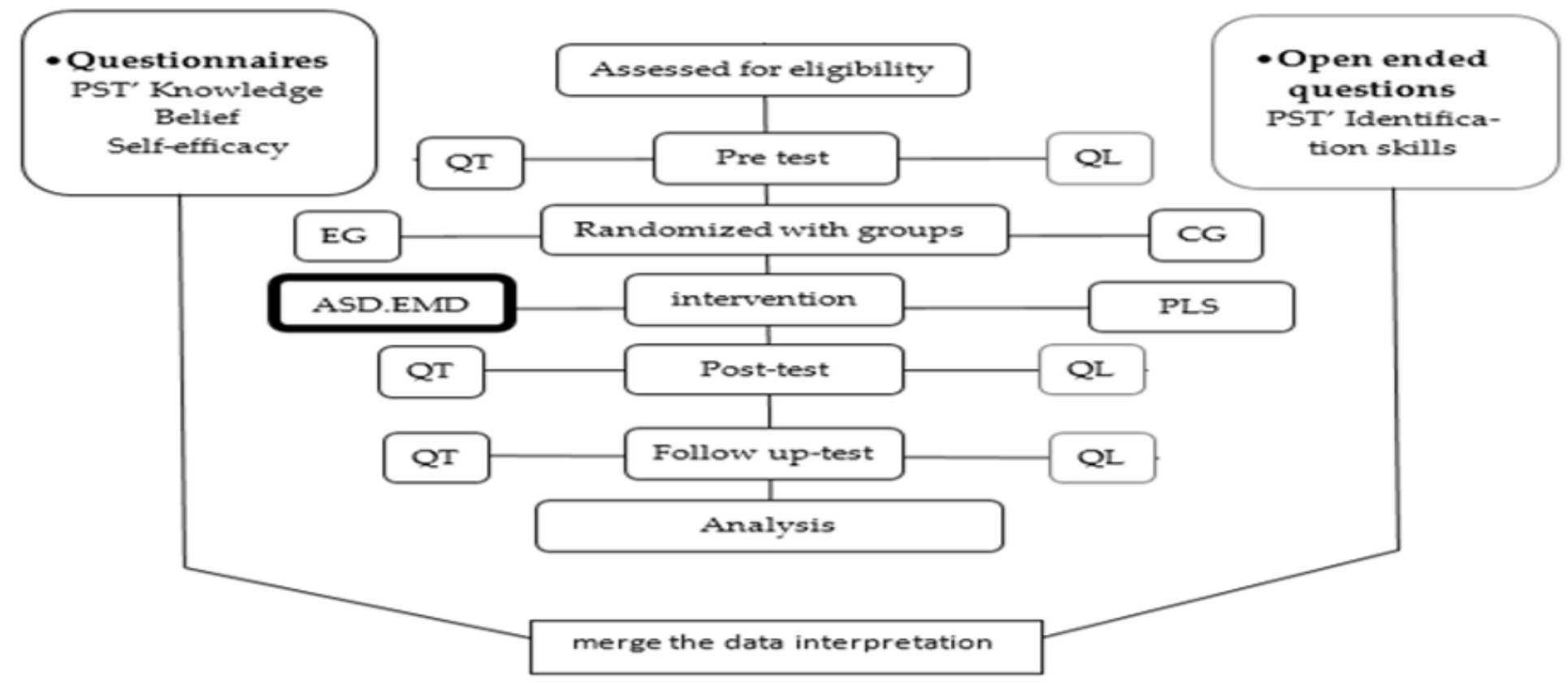

Figure 1

Convergent Parallel Mixed Method 


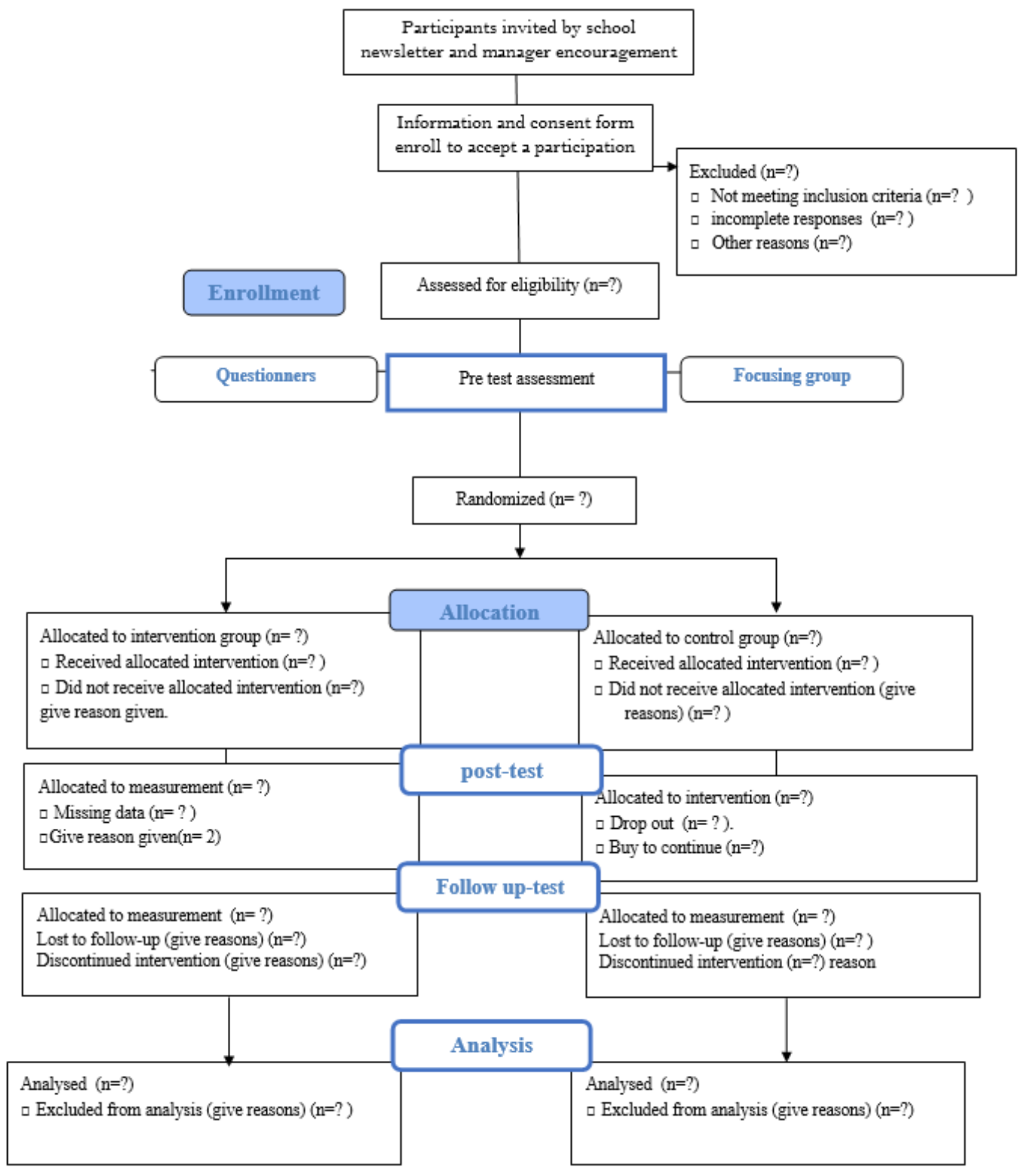

Consolidated Standards of Reporting Trials

\section{Figure 2}

Consolidated Standards of Reporting Trials

\section{Supplementary Files}

This is a list of supplementary files associated with this preprint. Click to download. 
- supplementaryfile1SPIRIT.doc

- supplementaryfile2DevelopingEMASD.docx

- supplementaryfile3COREQ.docx

- supplementaryfile4ethicalapproval.pdf 